\title{
Examining the Effectiveness of Direct Instruction on the Acquisition of Social Skills of Mentally Retarded Students in Regular Classroom Settings
}

\author{
Osman Özokcu' ${ }^{1}$, Gönül Akçamete ${ }^{2}$, Mehmet Özyürek ${ }^{3}$ \\ ${ }^{1}$ Faculty of Education, Inonu University, Malatya, Turkey \\ ${ }^{2}$ Atatürk Faculty of Education, Near East University, Lefkoşa, TRNC \\ ${ }^{3}$ Faculty of Education, International Cyprus University, Lefkoşa, TRNC \\ Correspondence: Osman Özokcu, Faculty of Education, Inonu University, Malatya, Turkey.
}

Received: January 7, 2017

doi:10.11114/jets.v5i4.2294
Accepted: February 23, 2017

Online Published: March 20, 2017

URL: https://doi.org/10.11114/jets.v5i4.2294

\begin{abstract}
The purpose of this study is to reveal whether or not the social skills teaching program based on the direct instruction approach is effective on the ability of mentally retarded students in regular classroom settings to gain social skills such as apologizing, asking for help and finishing a task on time, and to generalize these abilities. This study used the model of multiple-probe design between subjects which takes place in the research methods of single-subject design. The researchers carried out this study with one 12-year-old male student and two female students, ages 12 and 11 . To collect study data, this study used the teacher interview form, the social skills checklist, criterion-referenced measurement tools and data record tables. Graphical analyses were used to analyze data. To use target social skills (skills of apologizing, asking for help and finishing a task on time) in education, instructional plans that included acting as a model, guided practice and independent practice steps, which are the basic stages of the direct instruction approach, were prepared. In the social skills program, teaching sessions were held separately and conducted 3 days per week. At the end of the teaching sessions, generalization sessions took place. After this study, it was seen that the social skills teaching program based on the direct instruction approach was effective on the ability of three mentally retarded students to gain the target social skills and to generalize these abilities.
\end{abstract}

Keywords: social skills, direct instruction approach, integration, social skills teaching, regular classroom setting, mental retardation

\section{Introduction}

Integration is an arrangement that is made by providing special education and additional services with a personnel specially trained for students affected by a deficiency to synchronously continue their education in general education classes with their peers. Integration practices can only function as the least limited educational environment for individuals in the event that support for special education services are provided. Otherwise, this environment only enables individuals with a disability to be together with their peers (Batu \& Kircaali-Iftar, 2005). In Turkey, when the subject of integration is discussed, it only comes to mind that disabled children are placed in the same classrooms with their non-disabled peers and are enabled to follow the same education program with their peers. Regular education is the program of education where individuals affected by disabilities are educated with their peers without any adjustments (Ozyurek, 1989). Therefore, in Turkey, mentally retarded students are most often placed in regular education settings rather than integration environments.

The requirement of teaching social skills that support social acknowledgment and mutual peer interaction in children with disabilities is emphasized for integration programs to become effective and to increase disabled children's social acceptance. To be successful in school, children should have not only academic competence but also social competence (Gresham, 2001). For disabled children, to benefit most from academic instruction and integration environments, to prevent possible problem behaviors, to gain social skills which are necessary increase independent life skills, to have peer and teacher acceptance and interactions, it is required to administer social skills teaching programs which are prepared to meet these requirements (Gresham, 2001; Hundert \& Hougton, 1992).

Social skills are defined as socially acceptable learned behaviors that allow children/individuals, who are accepted as 
one of the most important outputs of the school process, to get positive reactions from society and to prevent from getting negative reactions. These skills make it easier for children to learn and become playmates. They also help them to develop friendships and to maintain these friendships. Social skills are also necessary for people to initiate a positive interaction with other people (Elliot \& Gresham, 1993). In other words, these are skills that facilitate children's adaptation to social life and improve their friendships and social acknowledgment. Greeting, listening, thanking, sitting at a desk properly, apologizing, helping and completing a task on time are a few examples of social skills.

Children making normal progress generally learn various social skills and gain social competence with maturation and accidental learning. Children learn these skills by observing the behaviors of other children, their parents and other adults, using them as a model and imitating them. Children gain attitudes that are proper to the culture in which they live without the necessity of additional education thanks to the fact that parents and teachers strengthen children's behaviors within the scope of social skills and that when children display these behaviors, they receive positive social reactions from the people around them (Sucuoglu \& Cifci, 2001).

In fact, it has been reported that students who are affected by mental deficiency and placed in general education classrooms do not gain social skills in natural environments as their peers do (Huang \& Cuvo, 1997, Sazak, 2003). These students in general education classrooms have difficulty in learning social skills in a way that their normally developed peers do. Consequently, their social acknowledgment and learning experiences are limited. Therefore, for mentally retarded students to receive education in environments with their peers and to benefit from regular classroom settings, it is necessary to use the planned and systematic methods that will involve social interactions between children with disabilities and non-disabled children.

Today, there are systematic teaching approaches for increasing mentally retarded children's social interactions, social acknowledgments or for helping them to display social behaviors (Hundert \&Hougton, 1992). These approaches include the direct instruction approach, the cognitive process approach, the cooperative instruction approach and peer mediated instruction approach (Agran \&Wehmeyer, 1999; Alptekin, 2010; Avcioglu, 2001; Cakır, 2006; Cifci, 2001; Emecen, 2011; Sargent, 1991; Sazak, 2003).

The direct instruction approach is a teacher-centered instruction and, in this approach, teachers are responsible for instruction of all students. The essential point of this intervention approach is to reward students' proper behaviors in the learning process and to show students how to display skills properly when they are inadequate. Skill instruction is repeated once or twice a week in 15- or 20-minute teaching sessions, and after a few weeks another skill instruction is taught. The teacher observes whether or not each skill learned is used in the classroom or school and rewards children who display the skill properly (Sucuoglu \& Kargin, 2006).

Several studies have shown that the direct instruction approach is effective in teaching social skills. It was stated that the direct instruction approach had an effect on individuals who were affected by mental deficiency in gaining skills of questioning (Knapczyk, 1989); of shaving, of going to work on time by getting enough sleep, of socially interacting, of obeying business rules, of saluting (Wheeler, Bates, Marshall, \& Miller 1988); and of establishing relationships among individuals, which is a required skill in the workplace environment (Chadsey-Rusch, Karlan, Riva, \& Rusch 1984). In Turkey, Alptekin (2010), Cakır (2006), Emecen (2011), and Unsal (2007) reported that the direct instruction approach was effective in gaining the social skills of talking on a phone properly, the social skills of sitting at a desk properly, raising their hand, sitting down while doing a task, the social skills of thanking and sharing, and the social skills of thanking, helping and asking for permission, respectively.

An analysis of studies on acquisition of social skills for individuals with disabilities in Turkey showed that, although the effects of various social skills' educational curricula administered by different methods on children with disabilities and non-disabled children were examined (Avcioglu, 2001; Cifci, 2001; Sazak, 2003), there are only two studies exploring the effect of the direct instruction approach (Cakır, 2006; Unsal, 2007). However, it has been seen that no study has been conducted to determine whether the direct instruction approach used for students in regular classroom settings helps the teaching program enable students to gain social skills and to generalize these skills teaching program. Thus, it is required to teach social skills to mentally retarded students in regular classroom settings and to conduct research for determining the effectiveness of instruction administered using the direct instruction approach.

The purpose of this study is to research the effectiveness of instruction given to mentally retarded students by using the direct instruction approach in regular classroom settings for gaining social skills (apologizing, asking for help and finishing a task on time) and in generalizing these abilities. To achieve this purpose, answers were sought for the following questions: a) Is instruction which is given to mentally retarded students by using the direct instruction approach in regular classroom settings effective for gaining social skills such as apologizing, asking for help and finishing a task on time and in generalizing these abilities? b) What are the opinions of participating students on the instruction offered by their classroom teachers using the direct instruction approach and on the social skills learned? 


\section{Method}

\subsection{Study Design}

This study used the model of multiple-probe design between subjects, which takes place in the research methods of single-subject design, to determine the effectiveness of the direct instruction approach for the acquisition of social skills (apologizing, asking for help and finishing a task on time) of mentally retarded students in regular classroom settings.

This model initially collects the baseline data from all three subjects simultaneously. After all of the baseline data show determination, the researchers initiate the application for the first subject. When the criterion is met for the first subject, probe sessions are placed in all conditions, and the researchers collect data from three consecutive sessions. It is expected that the probe data of the first subject meets the criterion, that the other subjects show similar characteristics with the baseline. After the probe sessions, the researchers initiate the application for the second subject. When the criterion is met for the second subject, again, probe sessions are placed for all subjects. Now the probe data of the first and second subjects meet the criterion, and so the third subject is really expected to show similarity with the baseline. This process is repeated for the third subject (Kircaali-Iftar \& Tekin, 1997).

\subsection{Dependent and Independent Variables}

The dependent variables of this study are learning levels of mentally retarded students in gaining skills of apologizing, asking for help and finishing a task on time. The independent variable of this study is the social skills teaching program based on the direct instruction approach which aims to teach skills of apologizing, asking for help and finishing a task on time.

\subsection{Subjects}

The subjects of this study were three students studying in Oguz-Kaan Elementary School in Ankara. First, the teacher interview form and social skills checklist were administered to teachers in school, and twelve students, who did not have ability to apologize, ask for help or finish a task on time, were determined. Then, among them, six students, who had the prerequisite reading and writing skills, could follow two- or three-step directions given and could verbally give answers, were determined. Considering the possibility of target student loss, of these six students, three were selected as permanent and three were selected as substitute. Information about the participating students are given below.

The subject numbered one (Ali) is a 12-year-old fifth-grade integration student. When school records were examined, according to the Stanford Binet Intelligence Scale, his intelligence quotient was determined to be 58, and it was reported that he had reading and writing skills. According to school records, information received from his special education teacher and the evaluation carried out by the researchers, Ali had reading and writing skills at a third-grade level and had only enough mathematics skills for solving story problems.

The subject numbered two (Elif) is a 12-year-old fifth-grade integration student. When school records were examined, according to the Stanford Binet Intelligence Scale, her intelligence quotient was determined to be 62, and as a result of the Oral Reading Test administered by the researchers, it was found that Elif had reading skills at a fourth-grade level. It was reported that she had skills of problem solving with four operations in mathematics.

The subject numbered three (Ceren) is an 11-year-old fifth-grade integration student. When school records were examined, according to the Stanford Binet Intelligence Scale, her intelligence quotient was determined to be 68 . The Oral Reading Test was administered to Ceren by the researchers, and it was found that she had reading skills at a third-grade level. It was also reported that Ceren had mathematic skills at a third-grade level.

\subsection{Setting}

Teaching applications of this study was performed in the resource room of Oguz-Kaan Elementary School in which this study was carried out. In the setting, there were two tables and two chairs for the student and the model teacher to sit down. To collect data, voice and image records were required. Therefore, a video camera and a computer were also placed in the room. Baseline data and all data regarding the teaching sessions, probe sessions and generalization sessions in this study were collected in the specified environment.

\subsection{Experimenter}

The application stage of this study was completely conducted by the first writer.

\subsection{Materials}

In the social skills teaching program based on the direct instruction approach, skills measurement tools and social skills scenarios videos were developed to collect baseline, teaching, probe and generalization data of the subjects on social skills. The developed measurement tools and videos were used together in each stage of the data collection process. While developing the social skills scenarios videos, firstly, the relevant literature was reviewed. Then, the experimenter 
prepared a total of six scenarios, three to be used in the starting, probe and end of sessions and three for the generalization sessions (Akkok, 1999; Sucuoglu \& Ciftci, 2001; Unsal, 2007). The experimenter shot videos for the prepared scenarios in a classroom of Oguz-Kaan Primary School where this study was conducted. This study consulted two experts working in the field of special education to determine whether the scenarios prepared for use in the teaching program were suitable for the social skills they intended to teach. Feedback of the experts showed that the social validity of the scenarios to be used in teaching the three social skills was high. A computer was used in the resource room to watch the prepared videos in each stage of the experimental process. A video camera was placed in this room near the door to record the studies, and this camera was used by an assistant teacher. Moreover, necessary materials to be used in each stage of the direct instruction approach were kept available in the classroom.

\subsection{General Procedure}

Before initiating the experiment process, a pilot study was conducted for this study. Then, the experiment process was started. In the experiment process, for each skill-apologizing, asking for help and finishing a task on time - this study placed the starting level, teaching and generalizing probes. In this study of gaining social skills by using the direct instruction approach, social skills teaching material was prepared. The experiment process lasted six weeks. Each teaching session was completed in about 20-25 minutes. Teaching sessions took place three days a week. This study began the teaching program with teaching the skill of apologizing, followed by teaching the skills of asking for help and finishing a task on time. The number of sessions for each skill were different from each other.

\subsubsection{Pilot Study}

Before initiating the experiment process, to determine whether or not the teaching materials prepared for the social skills were applicable, a pilot study was conducted. The pilot study for the developed teaching material and data collection tools was administered to a 12-year-old male student with slight mental retardation who had similar characteristics to the subjects. The researchers conducted the pilot study in the resource room which was to be used in the present study. A research assistant working in Ankara University and a special education teacher of Oguz-Kaan Primary School participated in the pilot study as observers. After the pilot study was completed, it was found that the social skills teaching material was applicable, and there was no need for adaptation.

\subsubsection{Baseline Sessions}

According to the multiple-probe design across subjects, before administering the teaching plan, to determine whether or not there was a change in the performance level, probe measurements were performed four times with the three students by using skills measurement tools. After baseline data were collected from the three subjects, the teaching plan was administered.

\subsubsection{Teaching Sessions}

The social skills teaching comprised stages such as an introduction to the lesson, motivation, acting as a model, guided practice and independence practice. Moreover, this study used a teacher working in the same school with the subjects to act as the live model for the stage of acting as a model during the teaching of each of the three skills. Before teaching, the live model was informed of what to do while acting as a model, and her/his role for the modeling stage was practiced a few times. Then, the teaching sessions were started.

\subsubsection{Introduction to Study and Motivation}

The experimenter introduced the materials to be used during the social skills teaching and the teacher acting as a live model. Then, the experimenter explained the study rules to the students and expressed that when they followed the rules, they would receive reinforcements which are known to be effective on the students. The experimenter stressed the importance of learning social skills with examples and stated what the experimenter and the assistant teacher, who would be acting as a live model, would do, what the student would do, and that the student would properly learn the social skill by the end of the teaching. After giving the information, the experimenter said "Let's start our work now" and the teaching process was started. In the first stage of the teaching, acting as a model took place. Then, this study continued with guided practice and independent practices.

\subsubsection{The stage of Acting as a Model}

In this stage, the experimenter gave information to the students about the study. It was also explained them what the experimenter and assistant teacher, who would act as a live model, would do, what the student would do and what the student would gain by the end of the teaching. The student was told that the experimenter and the live model would portray the skill together. Then, while the experimenter and assistant teacher stated each sub-skill step of the skill studied, they became models for the student by displaying those behaviors. After modeling, the experimenter told the student "It's your turn", and wanted him/her to perform the skill. When the student correctly responded with what the 
experimenter wanted, he/she was rewarded by verbal reinforcements such as "well done" or "good job". If the student did not respond or responded incorrectly, the model of the skill was performed again.

\subsubsection{Guided Practices Stage}

After the experimenter and the live model provided a sufficient number of models, the experimenter moved on to the guided practices. In the first part of this stage, a teaching session including clues took place. The experimenter wanted the student to perform the skill studied alone in this first part. In this stage, when necessary, the experimenter verbally gave clues by repeating sub-skill steps of the skills to the student. If the student cannot properly perform the skill even with the clues, the experimenter returned to the stage of acting as a model to ensure the student can perform the skill. If the student performed the skill after receiving verbal clues, he/she was reinforced. In the second part of the guided practice, the experimenter moved on to guided practices in which cue was drawn back. The experimenter gave new exercises to the student and wanted him/her to perform the skill. Proper reactions of the student were reinforced. And, if the reaction was missing or not proper, the experimenter returned to the practice in which cue was given.

\subsubsection{Independent Practices Stage}

In this stage, the responsibility of performing the skill was totally passed to the student. The experimenter gave the main directions regarding the skill studied to the student and wanted him/her to perform the skill. If the student responded properly, he/she was verbally reinforced. If the reaction was not proper or there was no reaction at all, the experimenter returned to the guided practice stage in which the cue was drawn back.

\subsubsection{Generalization}

This study included generalization sessions to determine whether or not the subjects can generalize their skills which were gained shortly after they had learned the skills of apologizing, asking for help and finishing a task on time in different social skills scenarios. This study collected generalization data in three consecutive sessions. During the collection period of generalization data, this study used skills measurement tools and social skills scenarios videos, which were specifically designed to collect generalization data.

\subsection{Reliability Analyses}

To determine the reliability of this study, inter-rater reliability and performance reliability analyses were performed. Data regarding both inter-rater reliability and performance reliability were collected after observers watched at least $20 \%$ of teaching sessions which were held for each social skill and were recorded by video camera. A doctorate student research assistant working in the Department of Special Education, Faculty of Educational Sciences, Ankara University and a senior student in the same department helped to collect inter-rater reliability data in this study. Then, the data of the researcher and independent observers was calculated using the formula of "Agreement/Agreement + Disagreement x 100" and the inter-rater reliability coefficient was found for each skill (Kircaali-Iftar \& Tekin, 1997). The inter-rater reliability of this study was found to be $96 \%$. In this study, data regarding the performance reliability were collected by a teacher working in a practice school as a special education teacher. Performance reliability was calculated by multiplying the division, obtained by dividing the observed teacher behaviors into the planned teacher behaviors, with 100. The experimenter found the performance reliability to be $100 \%$ for each of the three students.

\subsection{Social Validity}

The researchers prepared a semi-structured interview form to determine whether the social skills gained in the study were used by students in the classroom and school environment. This interview form was also used to determine whether these skills served them well. This form included five questions. Shortly after the experiment process was over, qualitative interviews with the teachers of the participating subjects were conducted, and voice recordings were taken during these interviews.

\subsection{Data Analysis}

The data obtained during this social skills teaching study conducted by the researcher with mentally retarded students were graphically analyzed. Line graphics, among graphical analyses methods, was used to analyze the data.

\section{Findings}

In this section, there are findings regarding the students' acquisition and generalization of the target skills. Moreover, the opinions of the teachers, who were working in the same school as the participating students with mental deficiencies, about the social validity of this study are also in this section.

\subsection{Effectiveness and Generalization Findings}

As it is seen in Figure 1, Ali, the subject numbered 1, participating in the teaching program for the skill of apologizing, performed the apologizing skill in the baseline at a level of $20 \%$ on average. At the beginning of the teaching session, 
the proper reaction level of Ali was determined to be $30 \%$. After the last teaching sessions, his proper reaction level was $100 \%$. In the second- and third-probe stages, it was seen that the proper reaction level of Ali was $100 \%$. According to Figure 1, the proper reaction percentage mean of Ali in the generalization sessions was determined to be $100 \%$.

Elif, the subject numbered 2, performed the apologizing skill in the baseline at a level of $20 \%$ on average. At the beginning of the teaching sessions, the proper reaction level of Elif was determined to be 30\%. After the last teaching session, her proper reaction level was $100 \%$. In the third- and fourth-probe stages, it was seen that the proper reaction level of Elif was $100 \%$. According to Figure 1, the proper reaction percentage mean of Elif in the generalization sessions was determined to be $100 \%$.

Ceren, the subject numbered 3, performed the apologizing skill in the baseline at a level of $20 \%$ on average. At the beginning of the teaching sessions, the proper reaction level of Ceren was determined to be $30 \%$. After the last teaching session, her proper reaction level was $100 \%$. In the third- and fourth-probe stages, it was seen that the proper reaction level of Ceren was $100 \%$. According to Figure 1, the proper reaction percentage mean of Ceren in the generalization sessions was determined to be $100 \%$.

As it is seen in Figure 2, Ali, the subject numbered 1, participating in the teaching program for the skill of asking for help, performed the asking for help skill in the baseline at a level of $20 \%$ on average. At the beginning of the teaching sessions, the proper reaction level of Ali was determined to be 30\%. After the last teaching session, his proper reaction level was $100 \%$. In the second- and third-probe stages, it was seen that the proper reaction level of Ali was $100 \%$. According to Figure 2, the proper reaction percentage mean of Ali in the generalization sessions was determined to be $100 \%$.

Elif, the subject numbered 2, performed the skill of asking for help in the baseline at a level of $20 \%$ on average. At the beginning of the teaching sessions, the proper reaction level of Elif was determined to be $20 \%$. After the last teaching session, her proper reaction level was $100 \%$. In the third- and fourth-probe stages, it was seen that the proper reaction level of Elif was $100 \%$. According to Figure 2, the proper reaction percentage mean of Elif in the generalization sessions was determined to be $100 \%$.

Ceren, the subject numbered 3, performed the skill of asking for help in the baseline at a level of $20 \%$ on average. At the beginning of the teaching sessions, the proper reaction level of Ceren was determined to be $40 \%$. After the last teaching session, her proper reaction level was $100 \%$. In the third- and fourth-probe stages, it was seen that the proper reaction level of Ceren was $100 \%$. According to Figure 2, the proper reaction percentage mean of Ceren in the generalization sessions was determined to be $100 \%$. 


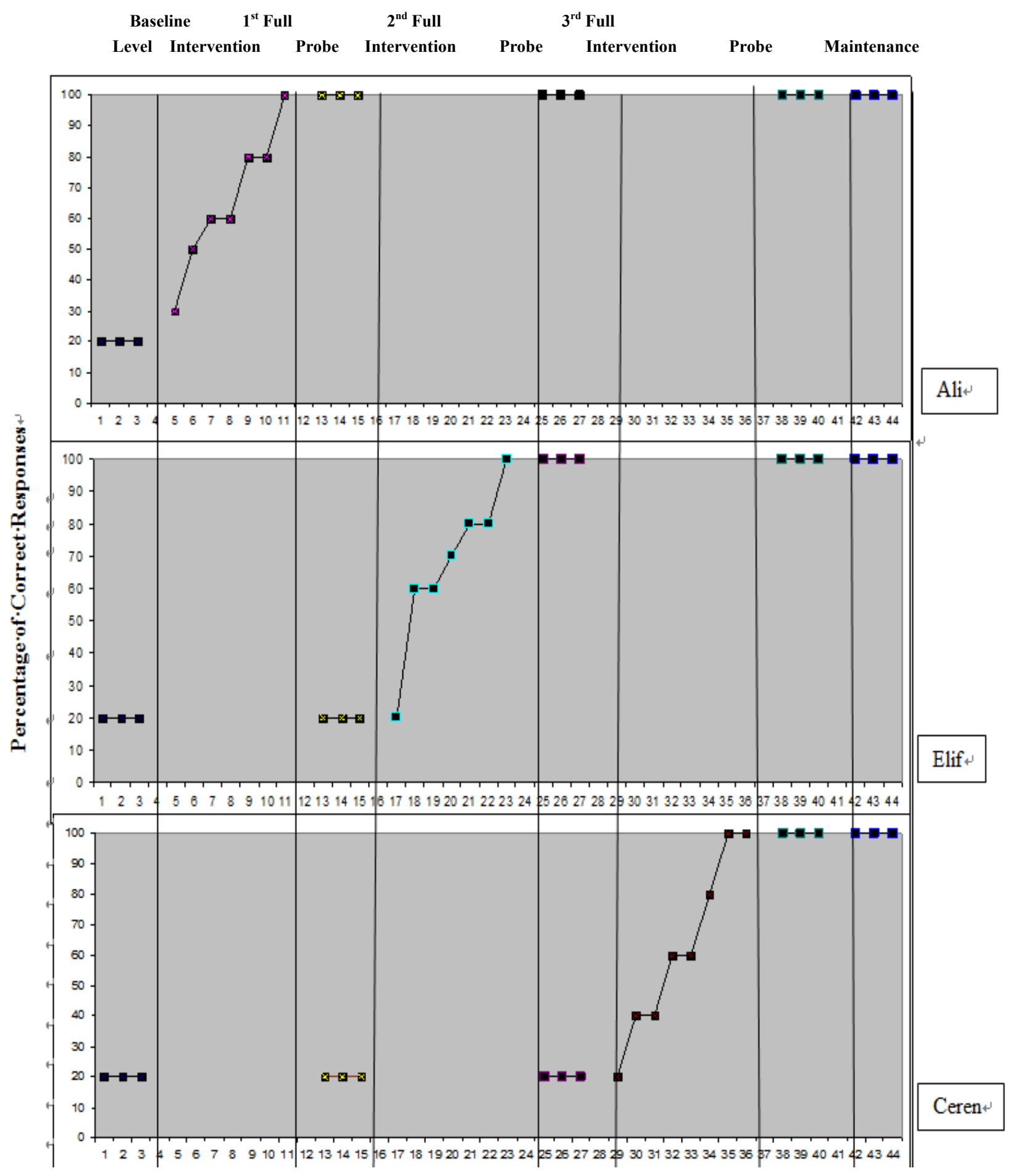

Sessions

Figure 1. Participants' apologizing learning levels 


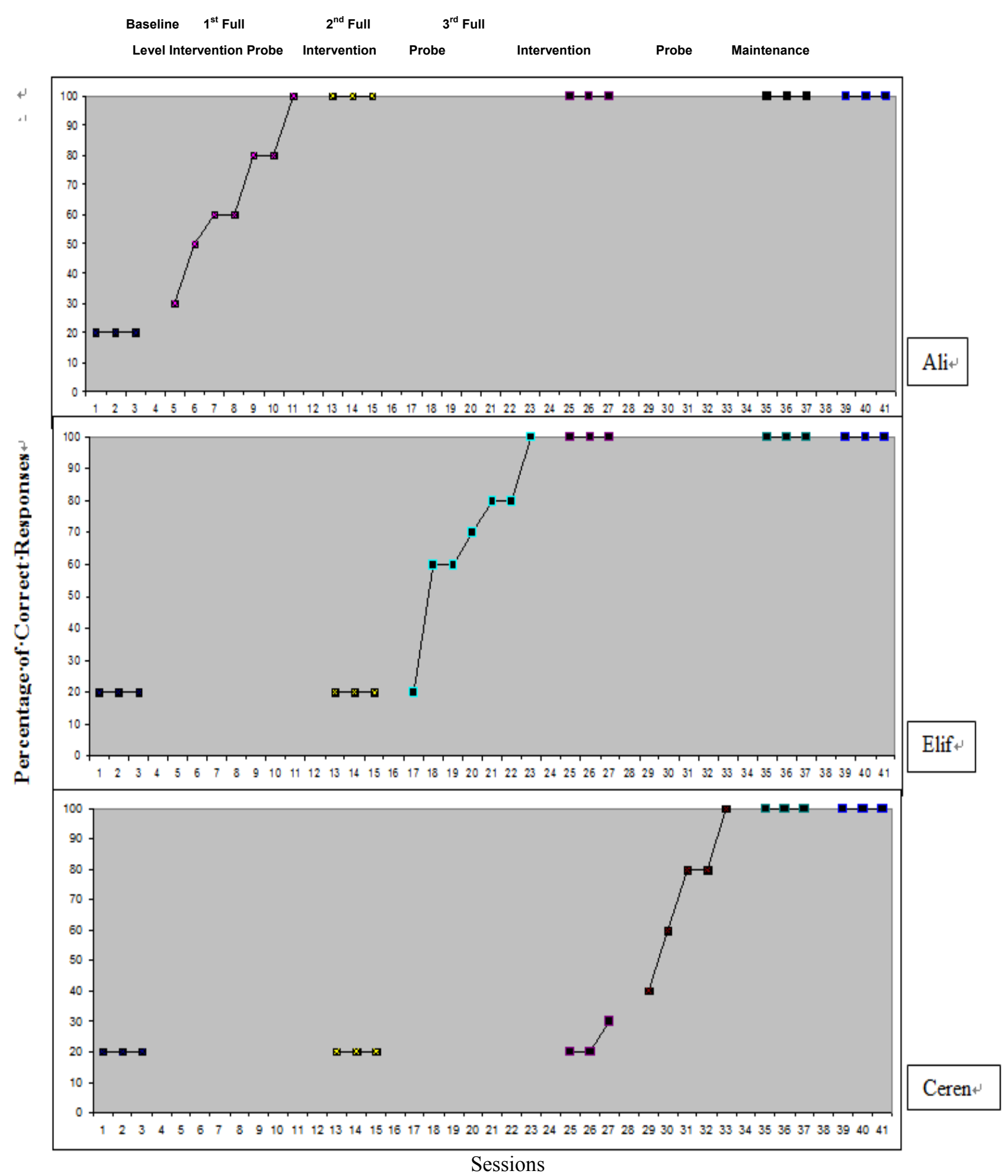

Figure 2. Participants' asking for help learning levels

As it is seen in Figure 3, Ali, the subject numbered 1, participating in the teaching program for the skill of finishing a task on time, performed the finishing a task on time skill in the baseline at a level of $20 \%$ on average. At the beginning of the teaching sessions, the proper reaction level of Ali was determined to be $30 \%$. After the last teaching session, his proper reaction level was $100 \%$. In the second- and third-probe stages, it was seen that the proper reaction level of Ali was $100 \%$. According to Figure 3, the proper reaction percentage mean of Ali in the generalization sessions was determined to be $100 \%$.

Elif, the subject numbered 2, performed the skill of finishing a task on time in the baseline at a level of $20 \%$ on average. At the beginning of the teaching sessions, the proper reaction level of Elif was determined to be $20 \%$. After the last teaching session, her proper reaction level was $100 \%$. In the third- and fourth-probe stages, it was seen that the proper 
reaction level of Elif was $100 \%$. According to Figure 3, the proper reaction percentage mean of Elif in the generalization sessions was determined to be $80 \%$.

Ceren, the subject numbered 3, performed the skill of finishing a task on time in the baseline at a level of $20 \%$ in average. And, at the last teaching session, her proper reaction level was $100 \%$. In the third- and fourth-probe stages, it was seen that the proper reaction level of Ceren was $100 \%$. According to Figure 3, the proper reaction percentage mean of Ceren in the generalization sessions was determined to be $80 \%$.

In conclusion, the study results have created an impression that the social skills teaching program which was prepared and presented based on the direct instruction approach had an effect on the participants in gaining three skills and generalizing them.

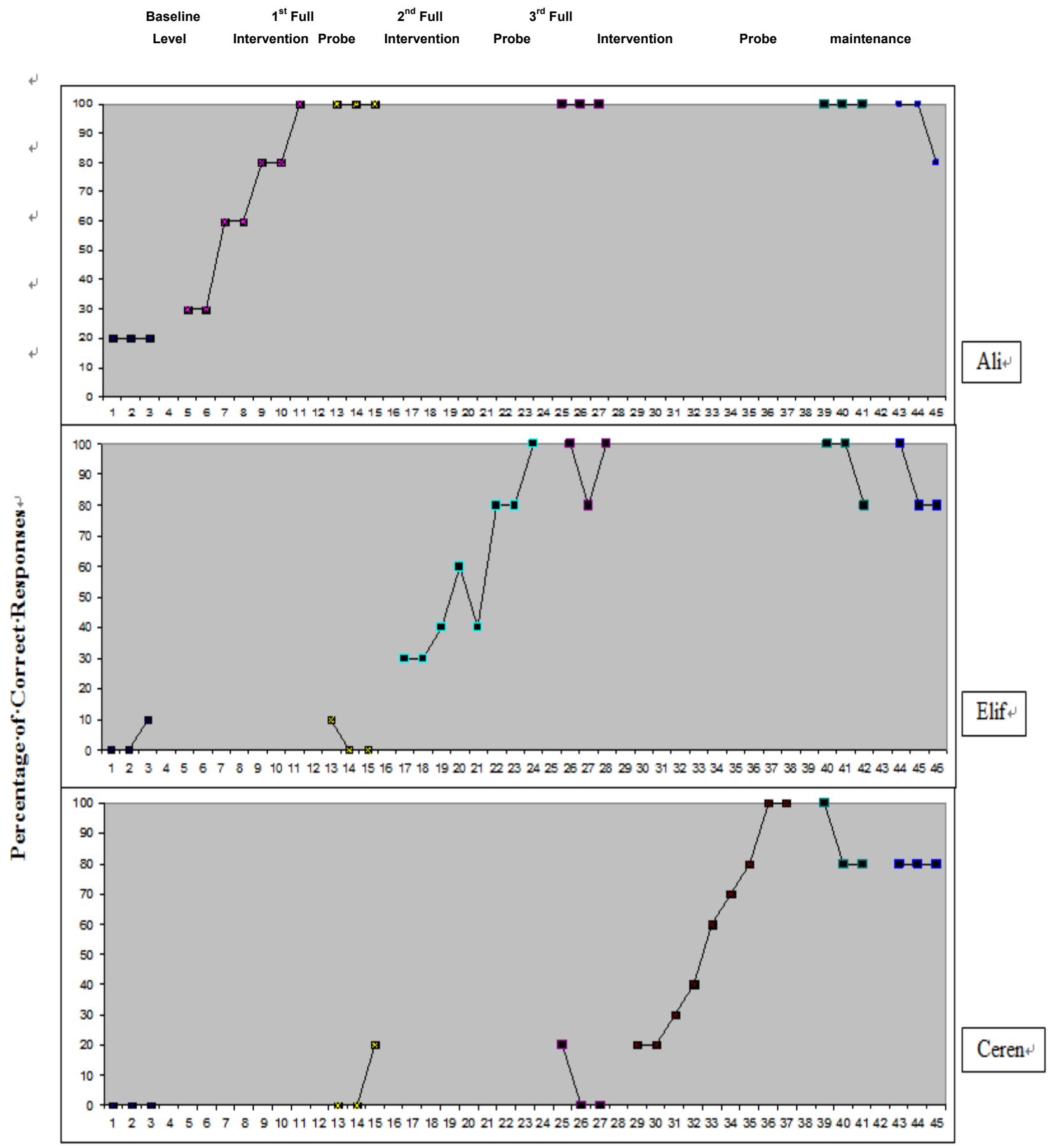

Sessions

Figure 3. Participants' completing a task on time learning levels 


\subsection{Social Validity Findings}

This study received the opinions of the target students and teachers regarding the teaching of the skills of apologizing, asking for help and finishing a task on time, which are the target skills of this study. Then, an inventory was taken of these opinions. These inventories were examined, and it was seen that the information received from the teachers were informative on the availability of the taught skills in natural environments. As a result of the analyses, the teachers' observations about the students are briefly presented below.

Although the number of observations of teachers were limited, the observations showed that the participating students used the learned social skills in the classroom environment. The fact that teachers gave even a little information regarding whether or not the social skills were used in a natural environment has shown that the social skills which were gained can be generalized in the classroom environment.

\section{Discussion}

This study was conducted to determine whether the teaching program based on the direct instruction approach has an effect on students with mental deficiencies in regular classroom settings in gaining the social skills of apologizing, asking for help and finishing a task on time.

This study showed that three mentally retarded students benefited from the social skills teaching program based on the direct instruction approach and that they learned the skills of apologizing, asking for help and finishing a task on time and can generalize these skills. The present study's findings show consistency with other study findings which have shown that mentally retarded individuals can gain various social skills by using the social skills teaching program developed based on the direct instruction approach (Alptekin, 2010; Cakir, 2006; Cashwell, Skinner, \& Smith, 2001; Emecen, 2011; Erwin, 1994; Rutherford, Mathur, \& Quinn, 1998; Sugai \& Lewis, 1996).

The finding regarding the fact that disabled students learned social skills as a result of administering the social skills teaching programs which are developed based on the direct instruction approach shows consistency with other findings in the literature. Kamps, Dugan, Potucek, \& Collins (1999) reported that three first-grade students with autism increased their social interaction after receiving the social skills teaching program, which was aimed to increase the students' social interaction with their peers by using the direct instruction approach. Hundret \& Hougton (1992) reported that disabled students studying in general education classrooms increased their social interaction after receiving the teaching program, which was provided for the skills of inviting others to join them in playing games, sharing and giving a compliment, and included the skills of acting as a model, giving feedback, rewarding and adult help. Matson, Fee, Coe, \& Smith (1991) conducted a study, which was based on the direct instruction approach, with twenty-eight 4- and 5 -year-old students with developmental retardation, and the researchers determined that students increased their social skills after the instruction for skills of greeting, asking for permission and initiating a game. McIntosh, Vaughn, \& Zaragoza (1991) reviewed a study on twenty-two social skills instruction, which was conducted with 572 students with learning disabilities. In these studies, the skills of direct instruction, acting as a model and giving feedback were in the scope of the social skills instruction programs. It was found that, among the studies, 14 had positive teaching effects.

Skills within the applied social skills teaching program based on the direct instruction approach are social skills that were determined as the necessity of students. While developing the program, the researchers thought that it was required to include the social skills which students need in the school and classroom environments. Therefore, the researchers met with participating subjects' teachers and observed the subjects in the classroom environment and during break times. This study determined which social skills mentally retarded students were inadequate with, and these were taught to the students by using the prepared teaching program. Thus, the direct instruction approach applied was thought to be effective because all the social skills gained by the students were social skills that produced positive results in the school environment.

This study not only included the social skills, which students need, while preparing the teaching program, but also took the social skills environments and situations that students will need during their lives into consideration while preparing the teaching materials. The content of the teaching materials was determined as a result of interviews with the students' teachers and observations made in the classroom and school environments. In teaching environments, providing education to students in natural settings, using live models, using problems which were suitable for the academic performances of the students and integrated into students' daily program and using real video scenarios caught students' attention and increased their motivation. The teaching program was considered effective because the teaching materials were prepared taking students' characteristics into consideration.

The direct instruction approach which was applied in this study included a one-on-one teaching method. In this method, to increase the social skills which students need for peer interaction, a teacher uses stages including acting a model, guided practice and independent practices and effectively uses strategies of acting as a model, helping, giving clues, 
providing feedback and reinforcement. In this study, students received direct instruction and were also continually reinforced for their behaviors. Students continually got feedback for their proper and wrong behaviors and were given opportunities to practice the social skills that they were intended to gain with guided and independent practices. The teaching program was considered to be effective because the direct instruction approach allows students to receive education in such a format (Brown \& Odom, 1994; Lausley \& Heflin, 2000; Mathur \& Rutherford, 1991).

It was seen that the number of teaching sessions in which some students participated as part of the social skills teaching program based on the direct instruction approach was more than others. Of the three mentally retarded students who participated in the teaching program for the apologizing skill, Ali and Elif learned this skill after seven sessions, while Ceren learned after participating in a total of five sessions. In the teaching program for the skill of asking for help, while Ali and Ceren learned after seven sessions, Ceren learned this skill after eight sessions. In the teaching program for the skill of finishing a task on time, Ali and Elif learned this skill after seven sessions, while Ceren learned after a total of nine sessions. Even if these students had similar characteristics such as meeting the same specified prerequisites, they had some differences in their learning abilities and motivation for studying. This could be the reason that the number of teaching sessions of the participating students with mental disabilities differed.

The researchers have reported that the success of the social skills teaching programs is directly related to the functionality of the programs. As well as meeting the requirements of the students to make these programs functional, determining problem behaviors and alternative social behaviors for problem behaviors, properly defining social behaviors to be taught, preparing social skills teaching programs, using appropriate evaluation and following methods increase the functionality and effectiveness of these programs (Sugai \& Lewis, 1996). The researchers have emphasized that teachers should be aware of the requirements of the students, should believe in the importance of social skills teaching and should include social skills in the education program to increase the success of social skills teaching programs (Maag \& Weber, 1995; Sugai \& Lewis, 1996, Warger \& Rutherford, 1993). In this study, target social skills were determined after interviewing with teachers, and three social skills which are important for teachers and regarded as essential for students were taught with academic skills. This situation may make it easier for students to gain the target social skills.

This study held generalization sessions for each skill taught after the teaching sessions were completed. An analysis of the generalization data showed that the subjects can generalize these skills when they encounter different scenarios from the video scenarios used in the teaching sessions. In this study, it was seen that the proper response percentages of the three subjects in the generalization sessions for the skills of the apologizing and asking for help were high. However, for the skill of finishing a task on time, while the proper response percentage of the first student, Ali, was quite high, the proper response percentages of the second and third students, Elif and Ceren, were found to be a little lower compared to Ali.

It is thought that the direct instruction approach in this study could increase mentally retarded students' success in the teaching and generalization sessions. The present study's findings are largely in agreement with the results seen in the previous studies. According to their study findings, Alptekin, (2010); Cakir; 2006; Emecen, (2011); Knapczyk (1989); Matson, Fee, Coe, \& Smith (1991) emphasized that subjects can continue to perform the social skills which they learned in the generalization and monitoring processes.

This study showed that students who participated in the teaching program can generalize the skills which they learned to different scenarios. However, it was not researched whether or not these students can generalize these skills to the environments and situations in which they should perform these skills. This can be considered as a limitation of this study. Further studies should research whether or not individuals can generalize social skills which they learned in real environments, and thus more detailed information about the functionality of the developed social skills teaching program will be received.

In conclusion, because the teaching practices using the direct instruction approach which used adult models was effective for students in gaining and generalizing social skills, it can be suggested to teachers and people working in this field to use this method for the teaching of social skills and the ability to generalize these skills to different equipment, people, and environments. It can also be suggested that the social skills teaching plans prepared based on the direct instruction approach in this study, skill measurement tools and social skills checklists should be used by teachers and people working in this field. Moreover, it can be suggested to administer the peer-mediated instruction program prepared according to the direct instruction approach and administer the teaching programs prepared based on the cognitive process approach or collaborative approach, then compare the effectiveness and efficiency between methods.

\section{Acknowledgement}

This research was based on a doctoral dissertation conducted by the first author under the supervision of the second and third authors. 


\section{References}

Agran, M., \& Wehmeyer, M. (1999). Teaching problem solving to student with mental retardation. Washington, DC: American Association on Mental Retardation.

Akkok, F. (1999). Developing social skills in schools. Istanbul: Ozgur publications.

Alptekin, S. (2010). The effect of direct instruction with modeling the social skills by the peers of the mentally retarded student on his/her acquiring, maintaining and generalizing the social skills and his/her social acceptance (Doctoral Dissertation). Gazi University Institute of Educational Sciences, Ankara, Turkey.

Avcioglu, H. (2001). Examining the effectiveness of program development for teaching social skills to hearing impairet students based on cooperative learning (Unpublished doctoral dissertation). Ankara University Institute of Educational Sciences, Ankara, Turkey.

Batu, E. S., \& Kırcaali-İftar, G. (2005). Inclusion. Ankara: Kök Publications.

Brown, W. H., \& Odom, S. L. (1995). Naturalistic peer intervention for promoting preschool children's social interactions. Preventing School Failure, 39(4), 38-42. https://doi.org/10.1080/1045988X.1995.9944641

Cakir, S. (2006). An investigation of effectiveness of the social skills training conducted through direct instruction approach for mentally retarded students (Unpublished master's thesis). Gazi University Institute of Educational Sciences, Ankara, Turkey.

Cashwell, T. H., Skinner, C. H., \& Smith, S. E. (2001). Increasing second grade students report of peers prosocial behaviors via direct instruction, group reinforcement and progress feedback: A replication and extension. Education and Treatment of Children, 24(29), 161-176.

Chadsey-Rusch, J., Karlan, G. R., Riva, M. T., \& Rusch, F. R. (1984). Competitive employment: Teaching conversational skills to adults who are mentally retarded. Mentally retarded. Mental Retardation, 22(5), 218-225.

Cifci, İ. (2001). The effectiveness of social skills training program based on cognitive process approach for mentally retarded individuals (Unpublished doctoral dissertation). Ankara University Institute of Educational Sciences, Ankara, Turkey.

Elliott, S. N., \& Gresham, F. M. (1993). Social skills interventions for children. Behavior Modification, 17(3), 287-313. https://doi.org/10.1177/01454455930173004

Emecen, D. D. (2011) Comparision of direct instruction and problem solving approach teaching social skills to children with mental retardation. Educational Sciences: Theory \& Practice, 11(3), 1414-1420.

Ervin, P. G. (1994). Effectiveness of social skill training with children: A meta-analytic study. Counselling Pyschology Qarterly, 7(3), 305-311. https://doi.org/10.1080/09515079408254154

Gresham, F. M. (2001). Social skills instruction for exceptional children. Theory into Practice, 21(2), 129-133. https://doi.org/10.1080/00405848209542994

Huang, W., \& Cuvo, A. J. (1997). Social skills training for adults with mental retardation in job-related settings. Behavior Modification, 21(1), 3-44. https://doi.org/10.1177/01454455970211001

Hundret, J., \& Hougton, A. (1992), Promoting social interaction of children with disabilities in integrated preschools: A failure to generalize. Exceptional Children, 58(4), 311-320.

Kamps M. D., Dugan E., Potucek J., \& Collins A. (1999). Effects of cross-age peer tutoring networks among students with autism and general education students. Journal of Behavioral Education, 9(2), 97-115. https://doi.org/10.1023/A:1022836900290

Kircaali-Iftar, G., \& Tekin, E. (1997). Single-subject research techniques. Ankara: Turkish Psychological Association Publications.

Knapczyk, D. R. (1989). Generalization of students question asking from special class to regular class settings. Journal of Applied Behavior Analysis, 22(1), 77-83. https://doi.org/10.1901/jaba.1989.22-77

Lausey, K. M., \& Heflin, J. L. (2000). Enhancing social skills of kindergarten children with autism through the training of multiple peer as tutors. Journal of Autism and Developmental Disorders, 30(3), 183-193. https://doi.org/10.1023/A:1005558101038

Maag, J.W., \& Webber, J. (1995). Promoting children's social development in general education classrooms. Preventing School Failure, 39(3), 13-20. https://doi.org/10.1080/1045988X.1995.9944629

Mathur, S. R., \& Rutherford, R.B., (1991). Peer-mediated interventions promoting social skills of children and youth 
with behavioral disorders. Education \& Treatment of Children, 14(3), 226-242.

Matson, J.L., Fee, V. E., Coe, D. A., \& Smith, D. (1991). A social skills program for developmentally delayed

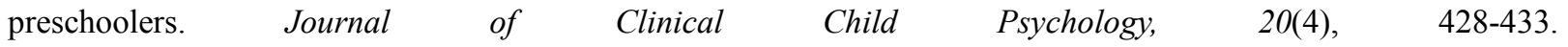
https://doi.org/10.1207/s15374424jccp2004_11

McIntosh, R., Vaughn, S., \& Zaragoza, N. (1991). A Review of a social interventions for student with learning disabilities. Journal of Learning Disabilities, 24(8), 451-458. https://doi.org/10.1177/002221949102400802

Ozyurek, M. (1989). Normalization on hearing impairment. Journal of Faculty of Educational Sciences, 2(2), 107-111.

Rutherford, R. B., Mathur, S. R., \& Quinn, M. M. (1988). Promoting social communication skills through cooperative learning and direct instruction. Education and Treatment of Children, 21(3), 354-368.

Sargent, L. R. (1991). Social skills for schools and community. Systematic instruction for children and youth with cognitive delays. Washington, DC: The Division on Mental Retardation of the Council for Exceptional Children.

Sazak, P. (2003). Examination of the effectiveness of peer-mediated social skills curriculum prepared for people with intellectual disabilities (Unpublished Master thesis). Abant Izzet Baysal University, Institute of Social Sciences, Bolu, Turkey.

Sucuoglu B., \& Kargin, T. (2006). Inclusion practices in primary schools: Approaches, methods, techniques. İstanbul: Morpa Publications.

Sucuoglu, B., \& Cifci, I. (2001). Can't do? Don't do? Social skill training for children with intellectual disabilities. Ankara University Press.

Sugai, G. L., \& Lewis, T. J. (1996). Preferred and promising practices for social skills instruction. Focus on Exceptional Children, 29(4), 1-23

Unsal, P. (2007). Comparing of the effectiveness of two different intervention approaches on social skills of the mainstreamed students (Unpublished doctoral dissertation). Ankara University Institute of Educational Sciences, Ankara, Turkey.

Warger, C. L., \& Rutherford, R. B. (1996). Social skills instruction: an essential component for learning. Washington: Foundation for Exceptional Innovations

Wheeler, J. J., Bates, P., Marshall, K. J., \& Miller, S. R. (1988). Teaching appropriate social behaviors to a young man with moderate mental retardation in a supported competitive employment settings. Education and Training in Mental Retardation, June, 105-116.

\section{Copyrights}

Copyright for this article is retained by the author(s), with first publication rights granted to the journal.

This is an open-access article distributed under the terms and conditions of the Creative Commons Attribution license which permits unrestricted use, distribution, and reproduction in any medium, provided the original work is properly cited. 